\title{
Third-generation cephalosporin-resistant spontaneous bacterial peritonitis: A single-centre experience and summary of existing studies
}

\author{
Jennifer Chaulk MD¹, Michelle Carbonneau NP MN RN¹, Hina Qamar MD¹, Adam Keough BSc ${ }^{1}$, Hsiu-Ju Chang MSc ${ }^{1}$, \\ Mang Ma MD FRCPC ${ }^{1}$, Deepali Kumar MD MSc FRCPC ${ }^{2}$, Puneeta Tandon MD MSc FRCPC ${ }^{1}$
}

\begin{abstract}
J Chaulk, M Carbonneau, H Qamar, et al. Third-generation cephalosporin-resistant spontaneous bacterial peritonitis: A single-centre experience and summary of existing studies. Can J Gastroenterol Hepatol 2014;28(2):83-88.
\end{abstract}

BACKGROUND: Spontaneous bacterial peritonitis (SBP) is the most prevalent bacterial infection in patients with cirrhosis. Although studies from Europe have reported significant rates of resistance to thirdgeneration cephalosporins, there are limited SBP-specific data from centres in North America.

OBJECTIVE: To evaluate the prevalence of, predictors for and clinical impact of third-generation cephalosporin-resistant SBP at a Canadian tertiary care centre, and to summarize the data in the context of the existing literature.

METHODS: SBP patients treated with both antibiotics and albumin therapy at a Canadian tertiary care hospital between 2003 and 2011 were retrospectively identified. Multivariate logistic regression was used to determine independent predictors of third-generation cephalosporin resistance and mortality.

RESULTS: In 192 patients, 25\% of infections were nosocomial. Forty per cent (77 of 192) of infections were culture positive; of these, 19\% (15 of 77) were resistant to third-generation cephalosporins. The prevalence of cephalosporin resistance was $8 \%$ with communityacquired infections, $17 \%$ with health care-associated infections and $41 \%$ with nosocomial acquisition. Nosocomial acquisition of infection was the only predictor of resistance to third-generation cephalosporins (OR 4.0 [95\% CI 1.04 to 15.2]). Thirty-day mortality censored for liver transplantation was $27 \%$ (50 of 184). In the 77 culture-positive patients, resistance to third-generation cephalosporins (OR 5.3 [1.3 to 22]) and the Model for End-stage Live Disease score (OR 1.14 [1.04 to 1.24]) were independent predictors of 30-day mortality.

CONCLUSIONS: Third-generation cephalosporin-resistant SBP is a common diagnosis and has an effect on clinical outcomes. In an attempt to reduce the mortality associated with resistance to empirical therapy, high-risk subgroups should receive broader empirical antibiotic coverage.

\section{Key Words: Antibiotic resistance; Cirrhosis; Infection; Nosocomial}

Spontaneous bacterial peritonitis (SBP) is the most prevalent bac$\checkmark$ terial infection in patients with cirrhosis $(1,2)$ and is diagnosed in one-quarter of cirrhotic patients hospitalized with bacterial infections (2). Existing guidelines recommend third-generation cephalosporins as the empirical therapy of choice in $\operatorname{SBP}(3,4)$. Studies from Europe (predominantly Spain) and Asia have challenged this recommendation based on subgroups of patients with high rates of third-generation cephalosporin-resistant infection (2,5-8), and data showing that inappropriate empirical antibiotic therapy is associated with increased morbidity and mortality $(2,9)$. The majority of the existing antibiotic resistance data are from Spain, a country well recognized to have

\section{Une péritonite bactérienne spontanée résistante aux céphalosporines de troisième génération : l'expérience d'un seul centre et le sommaire des études}

HISTORIQUE : La péritonite bactérienne spontanée (PBS) est l'infection bactérienne la plus prévalente chez les patients atteints d'une cirrhose. Même si des études menées en Europe ont fait état de taux significatifs de résistance aux céphalosporines de troisième génération, les données propres à la PBS provenant de centres nord-américains sont limitées.

OBJECTIF : Évaluer la prévalence, les prédicteurs et les conséquences cliniques de la PBS résistante aux céphalosporines de troisième génération dans un centre de santé canadien et résumer les données compte tenu des publications sur le sujet.

MÉTHODOLOGIE : Les chercheurs ont fait la recension rétrospective des patients ayant une PBS traités à la fois par des antibiotiques et de l'albumine dans un hôpital canadien de soins tertiaires entre 2003 et 2011. Ils ont utilisé la régression logistique multivariée pour déterminer les prédicteurs indépendants de résistance aux céphalosporines de troisième génération et la mortalité.

RÉSULTATS : Chez 192 patients, $25 \%$ des infections étaient d'origine nosocomiale. Quarante pour cent (77 cas sur 192) des infections étaient confirmée par culture; de ce nombre, 19 \% (15 cas sur 77) étaient résistants aux céphalosporines de troisième génération. La prévalence de résistance à la céphalosporine s'élevait à $8 \%$ des infections d'origine communautaire, à $17 \%$ des infections associées aux soins de santé et à $41 \%$ des infections d'origine nosocomiale. L'origine nosocomiale de l'infection était le seul prédicteur de la résistance aux céphalosporines de troisième génération (RRR 4,0 [95 \% IC 1,04 à 15,2]). La mortalité dans les 30 jours expurgée des transplantations hépatiques s'élevait à $27 \%$ (50 cas sur 184). Chez les 77 patients dont l'infection était confirmée par culture, la résistance aux céphalosporines de troisième génération (RRR 5,3 [1,3 à 22]) et le score du modèle d'insuffisance hépatique terminale (RRR 1,14 [1,04 à 1,24]) étaient des prédicteurs indépendants de mortalité dans les 30 jours.

CONCLUSIONS : La PBS résistante aux céphalosporines de troisième génération est un diagnostic courant qui a un effet sur les issues cliniques. Dans une tentative pour réduire la mortalité associée à la résistance à un traitement empirique, les sous-groupes à haut risque devraient recevoir un antibiotique empirique à plus large spectre.

\footnotetext{
${ }^{1}$ Division of Gastroenterology, Department of Medicine; ${ }^{2}$ Division of Infectious Diseases, Department of Medicine, University of Alberta, Edmonton, Alberta

Correspondence: Dr Puneeta Tandon, Division of Gastroenterology, Department of Medicine, University of Alberta, 130 University Campus, Edmonton,

Alberta T6G2X8. Telephone 780-492-9844, fax 780-492-9873, e-mail ptandon@ualberta.ca
}

Received for publication September 22, 2013. Accepted December 9, 2013

disproportionately high rates of antibiotic resistance (10-14). Before globalizing our local recommendations to broaden empirical antibiotic coverage in high-risk SBP subgroups, we aimed to evaluate the prevalence and predictors of third-generation cephalosporin resistance in SBP patients from our local tertiary care centre, and to interpret these data in the context of the existing literature.

Patients and study design

\section{METHODS}

The present analysis was a retrospective cohort study including patients with cirrhosis diagnosed with SBP between February 2003 and May 2011. 
Local ethics approval was obtained for retrospective data collection. Adult patients with cirrhosis (as determined by compatible radiology, laboratory markers and clinical presentation), a diagnosis of SBP, and treatment with both antibiotics and intravenous albumin therapy if criteria for high-risk were met (serum creatinine $\geq 88.4 \mu \mathrm{mol} / \mathrm{L}$ or serum bilirubin $\geq 68.1 \mu \mathrm{mol} / \mathrm{L})(3,4)$, were included. To avoid an overrepresentation of a single patient's demographic characteristics, only a single episode of SBP was included per patient. Due to the retrospective nature of the study, the type of antibiotics and dose of albumin given were at the discretion of the treating physician. Patients were excluded if they had undergone a previous liver transplant, or had secondary peritonitis, a malignant ascites or HIV infection. Due to the difficulties in identifying cases of SBP according to International Classification of Diseases codes, two sources to identify cases of SBP were used. First, local health records provided information on all paracenteses in which patients had a $>24$ h stay in the hospital $(n=2094)$. This enabled identification of patients who were diagnosed with SBP and then admitted after an outpatient paracentesis, and also those who were diagnosed with SBP in hospital. Second, the local hospital laboratory provided details of patients who had fluid polymorphonuclear cell counts $\geq 250$ cells $/ \mathrm{mm}^{3}(\mathrm{n}=642)$. All of these records were manually searched and cross-referenced, with removal of duplicate patients as well as patients not meeting inclusion and exclusion criteria. Many samples were removed because they were not ascites fluid (ie, joint aspirations), were ascites fluid but did not meet inclusion criteria (ie, secondary bacterial peritonitis, post-transplant ascites, malignant ascites) or because patients had not received albumin therapy. Patients were followed for 30 days after the diagnosis of SBP to determine outcomes.

\section{Definitions}

Spontaneous bacterial peritonitis was defined as an ascitic fluid cell count $\geq 250$ cells $/ \mathrm{mm}^{3}$, independent of culture results. Both culturepositive and culture-negative patients were included. Patients with ascitic fluid cultures positive for skin contaminants, such as coagulasenegative staphylococci, Bacillus species, Propionibacterium or Corynebacterium (7), were considered to be culture negative. Individuals with negative ascitic fluid cultures but positive blood cultures were considered to be culture positive (6). The site of SBP acquisition was characterized into one of three groups based on accepted definitions (2): community-acquired infection when the diagnosis was made within $48 \mathrm{~h}$ of hospitalization in patients not meeting criteria for health care-associated infection; health care-associated infection when the diagnosis was made within $48 \mathrm{~h}$ of hospitalization in patients who had contact with the health care system in the preceding 90 days (lived in a nursing home, on chronic hemodialysis or admitted to hospital for at least two days); and nosocomial infection - when the diagnosis was made after $>48 \mathrm{~h}$ of hospitalization. Organisms were deemed to be resistant to third-generation cephalosporins if this class of antibiotics was known to be ineffective for therapy (ie, Enterococcus), or if the organisms were resistant or had intermediate susceptibility on sensitivity testing. Broad-spectrum antibiotics were considered to be those with activity against both Gram-positive and Gram-negative organisms (ie, cephalosporins, carbapenems, piperacillin/tazobactam). Renal insufficiency was defined as a creatinine level $>132 \mu \mathrm{mol} / \mathrm{L}$ at any time from diagnosis to and including day 7 postdiagnosis. This value was chosen because it represents the threshold for a diagnosis of hepatorenal syndrome $(3,4)$ and has been the most commonly used value for defining acute kidney injury in previous studies evaluating SBP prognosis (15).

\section{Statistical analysis}

Patient characteristics were analyzed using descriptive statistics. Univariate and multivariate logistic regression analysis were used to determine independent predictors of third-generation cephalosporin resistance and 30-day mortality. Variables with $\mathrm{P}<0.10$ on univariate analysis were entered into the multivariable model. The results of the univariate and multivariate models were reported as OR and 95\% CIs.

\section{Patients and infection acquisition}

A total of 192 patients met the criteria for study inclusion. The median age was 54 years (interquartile range 48 to 63 years) and 66\% were male. The majority (76\%) had either alcohol or hepatitis $\mathrm{C}$ virus infection as the etiology of cirrhosis. The median Model for End-stage Liver Diseases (MELD) score at presentation was 20 (interquartile range 16 to 26). Sites of SBP infection were divided into nosocomial (25\%), health care associated (37.5\%) and community acquired (37.5\%). Twenty-eight per cent ( 54 of 192) of patients had exposure to antibiotics within the 30 days before the diagnosis of SBP and, of these, 56\% (30 of 54) were receiving fluoroquinolone (FQ) prophylaxis for SBP. The remaining baseline characteristics are presented in Table 1.

\section{Microbiology and patterns of antibiotic resistance}

Culture-positive infections were present in 77 of 192 (40\%) patients. Of these infections, 44 (57\%) were with Gram-positive bacteria and 15 (19\%) were resistant to third-generation cephalosporins (intrinsic or acquired resistance). The prevalence of antibiotic resistance increased from $8 \%$ (two of 25) in community-acquired infections to $17 \%$ (six of 35 ) in health care-associated infections, and up to $41 \%$ (seven of 17) in the setting of nosocomial acquisition (Table 2). Of the resistant organisms, 40\% (six of 15) were Enterococcus species, 27\% (four of 15) were Enterobacter and 20\% (three of 15) were extendedspectrum beta-lactamase-producing Escherichia coli. When cases were divided into two time periods according to date of SBP before or after 2008, there was no significant difference in the number of Grampositive, FQ-resistant or third-generation cephalosporin resistance between these time periods. Therefore, the remaining results were not separated into specific time periods.

\section{Predictors of resistance to third-generation cephalosporins}

In the 77 culture-positive patients, the predictors of resistance to third-generation cephalosporins (Table 3) were determined. As expected, the MELD score and the serum creatinine level were highly correlated variables. The likelihood ratio test was used to compare the association of each variable with cephalosporin resistance. Both associations were similar $(\mathrm{P}=0.07)$. MELD score was entered into the multivariate model over serum creatinine to provide a combined estimation of both liver and hepatic function. On multivariate analysis (Table 4), nosocomial acquisition of infection was the only predictor of resistance to third-generation cephalosporin antibiotics, with an OR of 4.0 (95\% CI 1.04 to 15.2). The use of FQ prophylaxis trended toward predicting resistance to FQ antibiotics (in patients on FQ prophylaxis, $92 \%$ of the SBP cases were resistant to FQ antibiotics whereas in patients not on FQ prophylaxis, $62 \%$ of SBP cases were resistant; $\mathrm{P}=0.08$ ) ; however, $\mathrm{FQ}$ use did not contribute to thirdgeneration cephalosporin resistance $(\mathrm{P}=0.6)$.

\section{Clinical impact of infection with third-generation cephalosporin- resistant organisms}

30-day mortality: Of the 192 patients, eight received a liver transplant within 30 days of presenting with SBP and were, therefore, excluded from the mortality analysis. In the remaining 184 patients, 30-day mortality was 50 of 184 (27\%). Cause of death was multisystem organ failure in $62 \%$ (31 of 50), sepsis in 30\% (15 of 50), variceal hemorrhage in $4 \%$ (two of 50); one case developed mesenteric ischemia and a second case developed a small bowel obstruction. In a univariate analysis, serum sodium, MELD score, bilirubin, creatinine and the peripheral leukocyte count were all strongly predictive of mortality. In a model in which the MELD score was entered over bilirubin and creatinine, MELD was the only independent predictor of mortality in the multivariate analysis including all 184 patients (OR 1.12 [1.06 to 1.19]; $\mathrm{P}=0.001$ ). The peripheral leukocyte count trended toward significance (OR 1.04 [0.99 to 1.09]; $\mathrm{P}=0.10$ ). There was no significant difference in 30-day mortality between the culture-positive and the culture-negative cases $(\mathrm{P}=0.24)$. 
TABLE 1

Baseline demographics $(n=192)$

\begin{tabular}{|c|c|c|c|}
\hline Variable* & All patients $(n=192)$ & $\begin{array}{l}\text { Resistant to third-generation } \\
\text { cephalosporins ( } n=15)\end{array}$ & $\begin{array}{c}\text { Culture negative OR not resistan } \\
\text { to third-generation } \\
\text { cephalosporins }(n=177)\end{array}$ \\
\hline Age, years & 54 (48 to 63$)$ & 55 (49 to 63$)$ & $54(47$ to 63$)$ \\
\hline \multicolumn{4}{|l|}{ Etiology of cirrhosis } \\
\hline Alcohol & $75(39)$ & $5(33)$ & $70(40)$ \\
\hline Hepatitis C & $70(36.5)$ & $4(27)$ & $66(37)$ \\
\hline Sodium, $\mathrm{mmol} / \mathrm{L}(\mathrm{n}=189)$ & $133(129.5$ to 136$)$ & 134 (129 to 136$)$ & 133 (130 to 137$)$ \\
\hline Peripheral blood leukocytes, $\times 10^{9} / L(n=190)$ & $10(5.7$ to 14.9$)$ & $5.8(4.7$ to 12$)$ & $10.2(6.1$ to 15.0$)$ \\
\hline International normalized ratio $(n=191)$ & $1.6(1.4$ to 1.9$)$ & 1.7 (1.4 to 2.1$)$ & $1.6(1.4$ to 1.9$)$ \\
\hline Bilirubin, $\mu \mathrm{mol} / \mathrm{L}(\mathrm{n}=191)$ & $73(37$ to 153$)$ & $73(53$ to 146$)$ & $73(36$ to 154$)$ \\
\hline Albumin, $g / L(n=184)$ & 27 (23 to 31$)$ & 29 (26 to 37$)$ & 26 (23 to 31$)$ \\
\hline Any antibiotic use within 30 days & $54(28)$ & $5(33)$ & $49(28)$ \\
\hline $\begin{array}{l}\text { Broad-spectrum antibiotic use within } 30 \text { days } \\
\text { (with or without fluoroquinolone prophylaxis) }\end{array}$ & $22(11.5)$ & $3(20)$ & $19(11)$ \\
\hline Fluoroquinolone prophylaxis & $30(16)$ & $3(20)$ & $27(15)$ \\
\hline Hepatocellular carcinoma & $21(11)$ & $2(13)$ & $19(11)$ \\
\hline Variceal bleed at presentation & $18(9)$ & $0(0)$ & $18(10)$ \\
\hline Diabetes mellitus & $31(16)$ & $1(7)$ & $30(17)$ \\
\hline Proton pump inhibitor use $(n=189)$ & $93(49)$ & $7(47)$ & $86(49)$ \\
\hline Culture positive & $77(40)$ & $15(100)$ & $62(35)$ \\
\hline Gram-positive, n/n (\%) & $44 / 77(57)$ & $7 / 15(47)$ & $37 / 62(60)$ \\
\hline Gram-negative, n/n (\%) & $33 / 77(43)$ & $8 / 15(53)$ & $25 / 62(40)$ \\
\hline
\end{tabular}

Data presented as median (interquartile range) or $n$ (\%) unless otherwise indicated. *Information available for all 192 patients, unless otherwise indicated

TABLE 2

Patterns of antibiotic resistance in culture-positive spontaneous bacterial peritonitis

\begin{tabular}{|c|c|c|c|c|}
\hline Microorganism & Community acquired $(n=25)$ & Health care associated $(n=35)$ & Nosocomial $(n=17)$ & Total $(n=77)$ \\
\hline \multicolumn{5}{|c|}{ Third-generation cephalosporin-resistant organisms $(n=15)$} \\
\hline & $2 / 25(8 \%)$ & $6 / 35(17 \%)$ & $7 / 17(41 \%)$ & - \\
\hline Viridans group Streptococci & 1 & 0 & 0 & 1 \\
\hline Enterococcus & 0 & 2 & 3 & 5 \\
\hline Vancomycin-resistant enterococcus & 0 & 0 & 1 & 1 \\
\hline Enterobacter & 0 & 2 & 2 & 4 \\
\hline ESBL Escherichia coli & 0 & 2 & 1 & 3 \\
\hline Bacteroides & 1 & 0 & 0 & 1 \\
\hline \multicolumn{5}{|c|}{ Third-generation cephalosporin-sensitive organisms $(n=62)$} \\
\hline & $23 / 25(92 \%)$ & $29 / 35(83 \%)$ & $10 / 17(59 \%)$ & - \\
\hline Streptococcus & 15 & 14 & 6 & 35 \\
\hline Staphylococcus aureus & 1 & 0 & 1 & 2 \\
\hline Escherichia coli & 3 & 12 & 2 & 17 \\
\hline Klebsiella & 4 & 2 & 1 & 7 \\
\hline Pseudomonas & 0 & 1 & 0 & 1 \\
\hline
\end{tabular}

ESBL Extended-spectrum beta-lactamase

To test the impact of third-generation cephalosporin resistance, the mortality analysis was performed again in the culture-positive patients. Of the subset of 77 culture-positive patients, four were excluded from the mortality analysis because they received a transplant within the 30-day follow-up period. Thirty-day mortality in the remaining 73 patients was $33 \%$ (24 of 73 ). Nine of the $13(69 \%)$ patients with cephalosporin resistance died by 30 days versus 25\% (15 of 60) of the culture-positive patients without cephalosporin resistance (unadjusted $\mathrm{P}=0.002\left[\chi^{2}\right.$ analysis]). Univariate and multivariate regression modelling is shown in Tables 5 and 6 . In multivariate analysis, resistance to third-generation cephalosporins (OR 5.3 [1.3 to 22]; $\mathrm{P}=0.02$ ) and the MELD score (OR 1.14 [1.04 to 1.24 ]; $\mathrm{P}=0.005$ ) were independently predictive of 30 -day mortality. Cause of death in these 24 patients was multisystem organ failure in 14 and sepsis in 10 . 


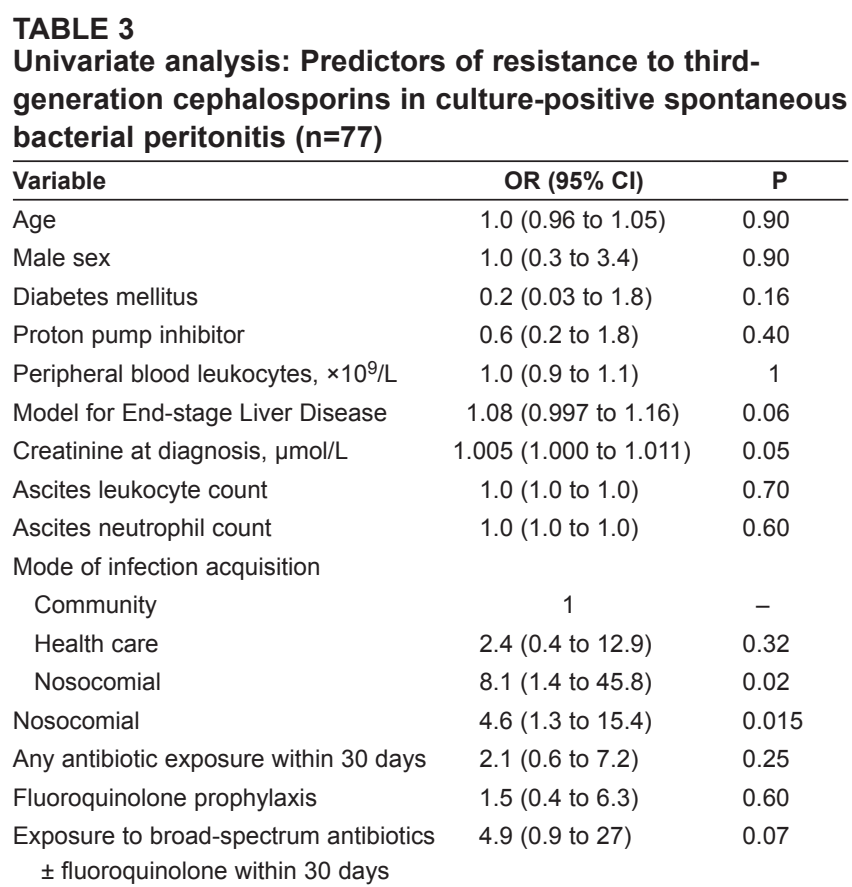

\section{TABLE 4}

Multivariate analysis: Predictors of resistance to thirdgeneration cephalosporins in culture-positive spontaneous bacterial peritonitis $(n=77)$

\begin{tabular}{llc}
\hline Variable & OR $(\mathbf{9 5} \% \mathbf{C I})$ & $\mathbf{P}$ \\
\hline Nosocomial infection & $4.0(1.04$ to 15.2$)$ & 0.04 \\
$\begin{array}{l}\text { Exposure to broad-spectrum antibiotics } \\
\quad \pm \text { fluoroquinolone within 30 days }\end{array}$ & $2.2(0.3$ to 15.7) & 0.40 \\
Model for End-stage Liver Disease & $1.08(0.99$ to 1.17) & 0.09 \\
\hline
\end{tabular}

Renal outcomes: Renal outcomes were evaluable in 187 of 192 (97\%) patients. Excluding the four patients on chronic hemodialysis and the one patient without creatinine data, the number of patients with renal insufficiency (creatinine $>132 \mu \mathrm{mol} / \mathrm{L}$ at anytime from diagnosis to and including day 7 postdiagnosis) was determined. Of these, 83 of 187 (44\%) met the threshold for diagnosis of renal insufficiency during the first seven days. A creatinine level $>132 \mu \mathrm{mol} / \mathrm{L}$ within the first seven days postdiagnosis was strongly associated with death within 30 days (51\% [40 of 79] versus 10\% [10 of 101]; $\mathrm{P}=0.001$ ).

When the culture-positive patients were considered, excluding the two patients on chronic hemodialysis, renal outcomes were evaluable in 75 of 77 (97\%). Forty-one per cent (31 of 75 ) had a creatinine level $>132 \mu \mathrm{mol} / \mathrm{L}$ at anytime from diagnosis to and including day 7 postdiagnosis. Of the evaluable culture-positive patients with thirdgeneration cephalosporin resistance, 62\% (eight of 13) developed renal insufficiency. Of the evaluable culture-positive patients without cephalosporin resistance, 37\% (23 of 62) developed renal insufficiency. This difference trended toward significance on $\chi^{2}$ analysis $(\mathrm{P}=0.10)$. Again, in this subgroup of culture-positive patients, a creatinine level $>132 \mu \mathrm{mol} / \mathrm{L}$ within the first seven days postdiagnosis was strongly associated with death within 30 days (59\% [17 of 29] versus $17 \%$ [seven of 42]; $\mathrm{P}=0.001$ ).

\section{DISCUSSION}

The present retrospective review of patients with SBP adds thirdgeneration cephalosporin resistance and outcome data from a Canadian tertiary care centre to the predominantly European data. It also provides a summary of the SBP-specific third-generation cephalosporin resistance data in the literature (Table 7) and identifies for the clinician three clinically relevant predictors of resistance to antibiotic therapy.
TABLE 5

Univariate analysis: Predictors of 30-day mortality in culture-positive spontaneous bacterial peritonitis $(n=73)^{*}$

\begin{tabular}{|c|c|c|}
\hline Variable & OR $(95 \% \mathrm{Cl})$ & $\mathbf{P}$ \\
\hline Age & $1.02(0.98$ to 1.06$)$ & 0.50 \\
\hline Male sex & $0.7(0.3$ to 2.1$)$ & 0.60 \\
\hline Sodium, $\mathrm{mmol} / \mathrm{L}$ & $0.98(0.89$ to 1.1$)$ & 0.70 \\
\hline Peripheral blood leukocytes, $\times 10^{9} / \mathrm{L}$ & $1.05(0.99$ to 1.12$)$ & 0.08 \\
\hline Albumin, $g / L$ & $0.99(0.91$ to 1.08$)$ & 0.80 \\
\hline Model for End-stage Liver Disease & $1.16(1.07$ to 1.27$)$ & 0.001 \\
\hline Creatinine at diagnosis, $\mu \mathrm{mol} / \mathrm{L}$ & $1.009(1.003$ to 1.015$)$ & 0.005 \\
\hline \multicolumn{3}{|l|}{ Infection acquisition } \\
\hline Community acquired & 1 & - \\
\hline Health care associated & $0.4(0.1$ to 1.2$)$ & 0.10 \\
\hline Nosocomial & $1.1(0.3$ to 3.9$)$ & 0.90 \\
\hline Nosocomial & $1.8(0.6$ to 5.7$)$ & 0.30 \\
\hline Variceal bleed at presentation & $1.0(0.6$ to 5.7$)$ & 1.0 \\
\hline $\begin{array}{l}\text { Resistance to third-generation } \\
\text { cephalosporin antibiotics }\end{array}$ & 6.8 (1.8 to 25$)$ & 0.004 \\
\hline \multicolumn{3}{|c|}{$\begin{array}{l}{ }^{\star} \text { Excluded four culture-positive patients transplanted within } 30 \text { days. Thirty-das } \\
\text { mortality rate }=24 / 73(33 \%)\end{array}$} \\
\hline \multicolumn{3}{|c|}{$\begin{array}{l}\text { TABLE } 6 \\
\text { Multivariate analysis: Predictors of } 30 \text {-day mortality in } \\
\text { culture-positive spontaneous bacterial peritonitis }(n=73)^{*}\end{array}$} \\
\hline Variable & OR $(95 \% \mathrm{Cl})$ & $\mathbf{P}$ \\
\hline Peripheral blood leukocytes, $\times 10^{9} / \mathrm{L}$ & $1.03(0.96$ to 1.11$)$ & 0.40 \\
\hline Model for End-stage Liver Disease & $1.14(1.04$ to 1.24$)$ & 0.005 \\
\hline $\begin{array}{l}\text { Resistance to third-generation } \\
\text { cephalosporin antibiotics }\end{array}$ & 5.3 (1.3 to 22$)$ & 0.02 \\
\hline
\end{tabular}

Nineteen per cent of our culture-positive SBP infections were resistant to third-generation cephalosporin antibiotics. This is consistent with the published literature, in which resistance rates between $11 \%$ and $45 \%$ have been reported $(2,6-8,16-18)$ (Table 7$)$. With such significant rates of resistance, and the implications for increased morbidity and mortality occurring as a result of inappropriate antibiotic therapy $(2,9)$, predictors of resistance to empirical antibiotic therapy should be considered when determining initial antibiotic therapy in SBP (19-22). Using both our local data and our review of the literature (Table 7), three important predictors of third-generation cephalosporin resistance are identified. Nosocomial acquisition of infection is the most consistent of these predictors $(2,6,7)$, attributed, in part, to more frequent antibiotic exposure as well as exposure to colonized/ infected personnel and the use of indwelling medical devices (urinary and intravascular catheters) in the nosocomial setting $(5,23)$. The recent use of cephalosporin antibiotics has also been recognized as an important predictor $(6,7)$. This variable was tested but was not predictive of resistance in our series, possibly because we limited our antibiotic exposure data collection to within the past 30 days (as opposed to 90 days). This was done in an attempt to enhance the accuracy of the data collected in a retrospective setting. Despite the lack of significance in our series, consistent with published series $(6,7)$ and consistent with infectious disease first principles, this variable should be considered to be a clinically relevant predictor. Importantly, unlike exposure to third-generation cephalosporins, FQ prophylaxis has not impacted the rates of third-generation cephalosporin-resistant SBP infections in our series or others (5). The third relevant predictor is recent colonization or infection with third-generation cephalosporin resistant organisms. Although the latter point was not tested in our group of patients, infection with resistant bacteria in the past three months has been recognized as an independent predictor of thirdgeneration cephalosporin resistance when considered in a series involving multiple types of bacterial infections in cirrhosis and is consistent with infectious disease first principles (2). 
TABLE 7

Summary of recent studies (in which the majority of patients with spontaneous bacterial peritonitis [SBP] were recruited within the past 10 years)

\begin{tabular}{|c|c|c|c|c|c|c|c|c|c|}
\hline & \multicolumn{9}{|c|}{ First author (reference), country; years data collected } \\
\hline & $\begin{array}{l}\text { Angeloni (25), } \\
\text { Italy; } \\
\text { 2004-2007 }\end{array}$ & $\begin{array}{c}\text { Ariza (6), } \\
\text { Spain; } \\
\text { 2001-2009 }\end{array}$ & $\begin{array}{c}\text { Cheong (7), } \\
\text { Korea; } \\
\text { 2000-2009 }\end{array}$ & $\begin{array}{l}\text { Present study, } \\
\text { Canada; } \\
\text { 2003-2011 }\end{array}$ & $\begin{array}{l}\text { Fernandez } \\
\text { (2), Spain; } \\
\text { 2005-2007 }\end{array}$ & $\begin{array}{c}\text { Heo (17), } \\
\text { Korea; } \\
\text { 2005-2006 }\end{array}$ & $\begin{array}{l}\text { Novovic (8), } \\
\text { Denmark; } \\
2000-2006\end{array}$ & $\begin{array}{l}\text { Umgelter (16), } \\
\text { Germany; } \\
\text { 2002-2006 }\end{array}$ & $\begin{array}{l}\text { Tandon (18), } \\
\text { United States; } \\
\text { 2009-2010 }\end{array}$ \\
\hline $\begin{array}{l}\text { Prevalence of third- } \\
\text { generation cephalosporin } \\
\text { resistance reported }\end{array}$ & $\checkmark$ & $\checkmark$ & $\begin{array}{l}\checkmark \text { (only for } \\
\text { Gram- } \\
\text { negative } \\
\text { SBP) }\end{array}$ & $\checkmark$ & $\checkmark$ & $\begin{array}{l}\checkmark \text { (only for } \\
\text { Gram- } \\
\text { negative } \\
\text { SBP) }\end{array}$ & $\checkmark$ & $\checkmark$ & $\checkmark$ \\
\hline Overall, n/n (\%) & $4 / 9(44)$ & $53 / 246(22)$ & 28/172 (16) & $15 / 77(19)$ & & $6 / 54(11)$ & $80 / 187(43)$ & $14 / 42(33)$ & $5 / 11(45)$ \\
\hline Community acquired, \% & & 7 & 10 & 8 & 2 & & 33 & & 17 \\
\hline Health care acquired, \% & & 21 & & 17 & 5 & & & & \\
\hline Nosocomial acquired, \% & & 41 & 41 & 41 & 22 & & 60 & & 80 \\
\hline $\begin{array}{l}\text { Independent predictors of } \\
\text { third-generation } \\
\text { cephalosporin resistance } \\
\text { reported (culture-positive } \\
\text { infections) }\end{array}$ & $x$ & $\checkmark$ & $\begin{array}{l}\checkmark \text { (only for } \\
\text { Gram- } \\
\text { negative } \\
\text { SBP) }\end{array}$ & $\checkmark$ & $\begin{array}{l}\times \text { (not tested } \\
\text { for SBP } \\
\text { infection } \\
\text { alone) }\end{array}$ & $x$ & $x$ & $x$ & $\begin{array}{l}\times \text { (not tested } \\
\text { for SBP } \\
\text { infection } \\
\text { alone) }\end{array}$ \\
\hline Nosocomial infection & & $\checkmark$ & $\checkmark$ & $\checkmark$ & & & & & \\
\hline $\begin{array}{l}\text { Cephalosporin use within } \\
\text { the past three months }\end{array}$ & & $\checkmark$ & $\checkmark$ & $x$ & & & & & \\
\hline Other & & $\begin{array}{l}\text { Ascites } \\
\text { neutrophils } \\
\text { diabetes } \\
\text { UGI bleed }\end{array}$ & $\begin{array}{l}\text { Acute renal } \\
\text { failure }\end{array}$ & & & & & & \\
\hline
\end{tabular}

UGI Upper gastrointestinal

In addition to being common, infection with third-generation cephalosporin-resistant organisms has a significant impact on clinical outcomes. In the culture-positive SBP cases in our series, infection with organisms resistant to empirical therapy increased the odds of death by a factor of 5.3. Importantly, this was independent of the MELD score. Sixty-nine per cent of the patients infected with thirdgeneration cephalosporin-resistant organisms died within 30 days. Moreover, patients infected with third-generation cephalosporinresistant organisms trended to having higher rates of renal insufficiency in the first seven days of SBP diagnosis. These data are supported by the existing literature $(2,7,9)$.

Therefore, based on evaluation of our local data and our review of the existing literature, we plan to modify our local empirical therapy of patients presenting with SBP. As per recommendations from Fernandez et al $(2,24)$, we support the use of carbapenem antibiotics as first-line therapy in patients presenting with nosocomial SBP. Based on infectious disease first principles and literature review, we propose to extend this broad-spectrum coverage to patients who have had exposure to cephalosporin antibiotics in the past 90 days and to patients who are known to be colonized or have had infections with organisms resistant to third-generation cephalosporins in the past 90 days. As with all infections, once antibiotic susceptibilities are available, antibiotic coverage should be narrowed.

The limitations of the current study should be acknowledged. First, it was retrospective in nature and, therefore, although all attempts were made to identify SBP cases, it is probable that some cases were missed. Second, although it can also be regarded as a strength, the sample size of the current study was decreased by the exclusion of cases not receiving antibiotic therapy or in high-risk cases $(3,4)$, intravenous albumin therapy. Third, conclusions were drawn from the small number of culture-positive cases that were resistant to thirdgeneration cephalosporin antibiotics (15 of 77). Despite the small number of cases, our recommendations for local changes in empirical antibiotic therapy are consistent with other studies in the area, particularly with regard to the importance of nosocomial acquisition of infection as a predictor of resistance to third-generation cephalosporin antibiotics. Because rates of resistance are known to vary with centre-dependent antibiotic use patterns and antibiotic stewardship guidelines, it is probable that some centres, particularly smaller ones, may not have rates of antibiotic resistance as high. Ideally, individual centres should collaborate with experts in microbiology and infections to confirm the generalizability of our findings to their own sites.

\section{CONCLUSION}

Third-generation cephalosporin-resistant SBP is a common problem, occurring in one of every five culture-positive SBP cases at our centre and up to $45 \%$ in published series. In addition to being common, resistance to third-generation cephalosporins is an independent predictor of mortality in patients with SBP. In an attempt to reduce the mortality associated with third-generation cephalosporin resistance, we plan to modify our local empirical SBP therapy algorithm. Subgroups at high risk for third-generation cephalosporin resistance (nosocomial infections, exposure to cephalosporin antibiotics within 90 days, infection/colonization with cephalosporin-resistant organisms within 90 days) will be given broader empirical antibiotic regimens. The impact of these recommendations on clinical outcomes will require prospective evaluation. Although the identified risk predictors may serve as a guide for many hospitals, ideally, individual sites should evaluate these in the context of their site-specific microbiological SBP profiles and resistance patterns.

\section{KEY MESSAGES}

- One in five SBP patients treated at our Canadian tertiary care hospital site are resistant to third-generation cephalosporin antibiotics.

- Third-generation cephalosporin-resistant SBP is an independent predictor of 30-day mortality.

- In an attempt to reduce mortality associated with resistance we suggest that high-risk subgroups receive broader empirical antibiotic coverage. These high-risk subgroups include SBP patients with nosocomial infection; colonization/infection with third-generation cephalosporin-resistant organisms within the past 90 days; and the use of cephalosporin antibiotics within the past 90 days. 


\section{REFERENCES}

1. Tandon P, Garcia-Tsao G. Bacterial infections, sepsis, and multiorgan failure in cirrhosis. Semin Liver Dis 2008;28:26-42.

2. Fernandez J, Acevedo J, Castro M, et al. Prevalence and risk factors of infections by multiresistant bacteria in cirrhosis: A prospective study. Hepatology 2012;55:1551-61.

3. EASL clinical practice guidelines on the management of ascites, spontaneous bacterial peritonitis, and hepatorenal syndrome in cirrhosis. J Hepatol 2010;53:397-417.

4. Runyon BA. Management of adult patients with ascites due to cirrhosis: An update. Hepatology 2009;49:2087-107.

5. Fernandez J, Navasa M, Gomez J, et al. Bacterial infections in cirrhosis: Epidemiological changes with invasive procedures and norfloxacin prophylaxis. Hepatology 2002;35:140-8.

6. Ariza X, Castellote J, Lora-Tamayo J, et al. Risk factors for resistance to ceftriaxone and its impact on mortality in community, healthcare and nosocomial spontaneous bacterial peritonitis. J Hepatol 2012;56:825-32.

7. Cheong HS, Kang CI, Lee JA, et al. Clinical significance and outcome of nosocomial acquisition of spontaneous bacterial peritonitis in patients with liver cirrhosis. Clin Infect Dis 2009;48:1230-6.

8. Novovic S, Semb S, Olsen H, Moser C, Knudsen JD, Homann C. First-line treatment with cephalosporins in spontaneous bacterial peritonitis provides poor antibiotic coverage. Scand J Gastroenterol 2012;47:212-6.

9. Kumar A, Ellis P, Arabi Y, et al. Initiation of inappropriate antimicrobial therapy results in a fivefold reduction of survival in human septic shock. Chest 2009;136:1237-48.

10. Baquero F. Antibiotic resistance in Spain: What can be done? Task Force of the General Direction for Health Planning of the Spanish Ministry of Health. Clin Infect Dis 1996;23:819-23.

11. Turner PJ. Extended-spectrum beta-lactamases. Clin Infect Dis 2005;41(Suppl 4):S273-S5.

12. Levy SB, O'Brien TF. Global antimicrobial resistance alerts and implications. Clin Infect Dis 2005;41(Suppl 4):S219-S20.

13. Levy SB. Antibiotic resistance worldwide - a Spanish task force responds. Clin Infect Dis 1996;23:824-6.
14. European Antimicrobial Resistance Surveillance System, Annual Report < www.ecdc.europa.eu/en/publications/Publications/ antimicrobial-resistance-surveillance-europe-2011.pdf> (Accessed April 9, 2012).

15. Tandon P, Garcia-Tsao G. Renal dysfunction is the most important independent predictor of mortality in cirrhotic patients with spontaneous bacterial peritonitis. Clin Gastroenterol Hepatol 2011;9:260-5.

16. Umgelter A, Reindl W, Miedaner M, Schmid RM, Huber W. Failure of current antibiotic first-line regimens and mortality in hospitalized patients with spontaneous bacterial peritonitis. Infection 2009;37:2-8.

17. Heo J, Seo YS, Yim HJ, et al. Clinical features and prognosis of spontaneous bacterial peritonitis in korean patients with liver cirrhosis: A multicenter retrospective study. Gut Liver 2009;3:197-204.

18. Tandon P, Delisle A, Topal JE, Garcia-Tsao G. High prevalence of antibiotic-resistant bacterial infections among patients with cirrhosis at a US liver center. Clin Gastroenterol Hepatol 2012;10:1291-8.

19. Bartlett JG. A call to arms: The imperative for antimicrobial stewardship. Clin Infect Dis 2011;53(Suppl 1):S4-7.

20. Doron S, Davidson LE. Antimicrobial stewardship. Mayo Clin Proc 2011;86:1113-23.

21. French GL. The continuing crisis in antibiotic resistance. Int J Antimicrob Agents 2010;36(Suppl 3):S3-7.

22. Nicolau DP. Current challenges in the management of the infected patient. Curr Opin Infect Dis 2011;24 (Suppl 1):S1-10.

23. Siegel JD, Rhinehart E, Jackson M, Chiarello L. Management of multidrug-resistant organisms in health care settings, 2006. Am J Infect Control 2007;35(10 Suppl 2):S165-S93.

24. Fernandez J, Gustot T. Management of bacterial infections in cirrhosis. J Hepatol 2012;56(Suppl 1):S1-12.

25. Angeloni S, Leboffe C, Parente A, et al. Efficacy of current guidelines for the treatment of spontaneous bacterial peritonitis in the clinical practice. World J Gastroenterol 2008;14:2757-62. 


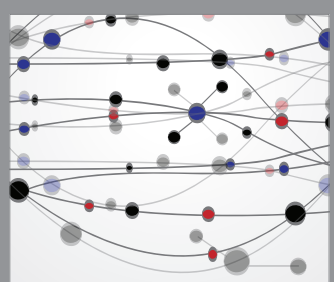

The Scientific World Journal
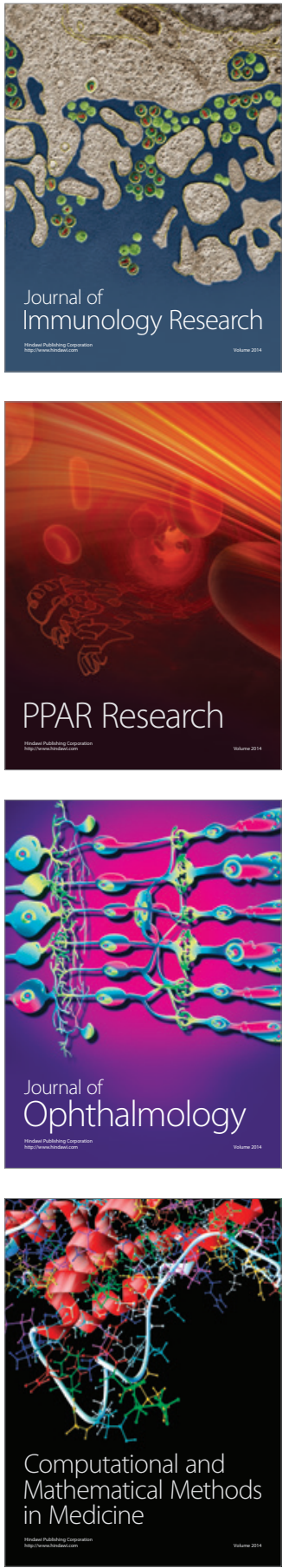

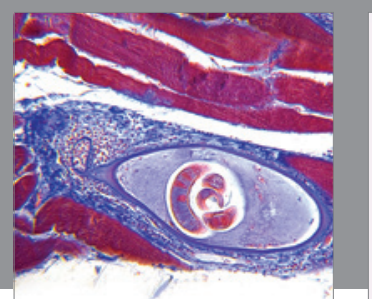

Gastroenterology Research and Practice

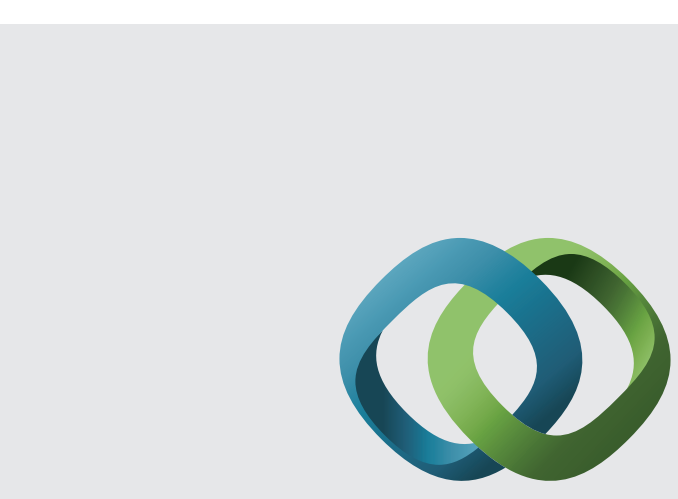

\section{Hindawi}

Submit your manuscripts at

http://www.hindawi.com
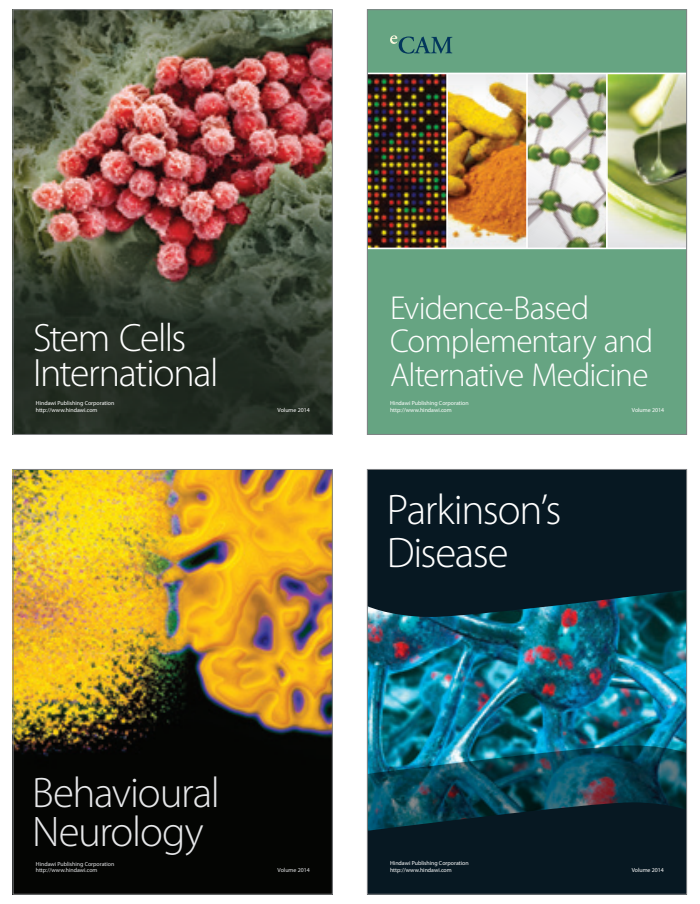
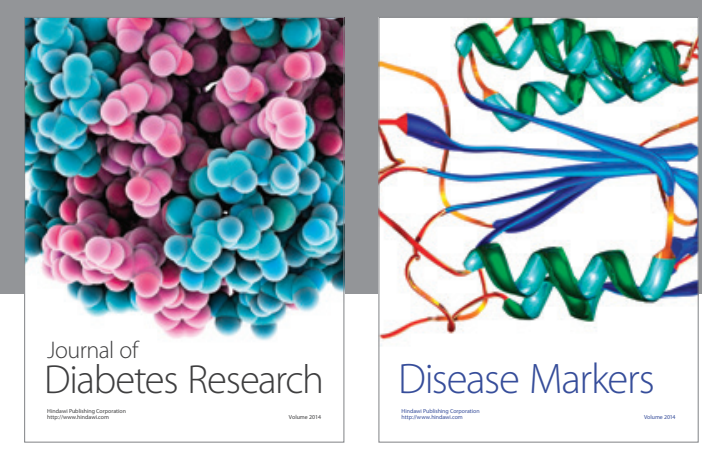

Disease Markers
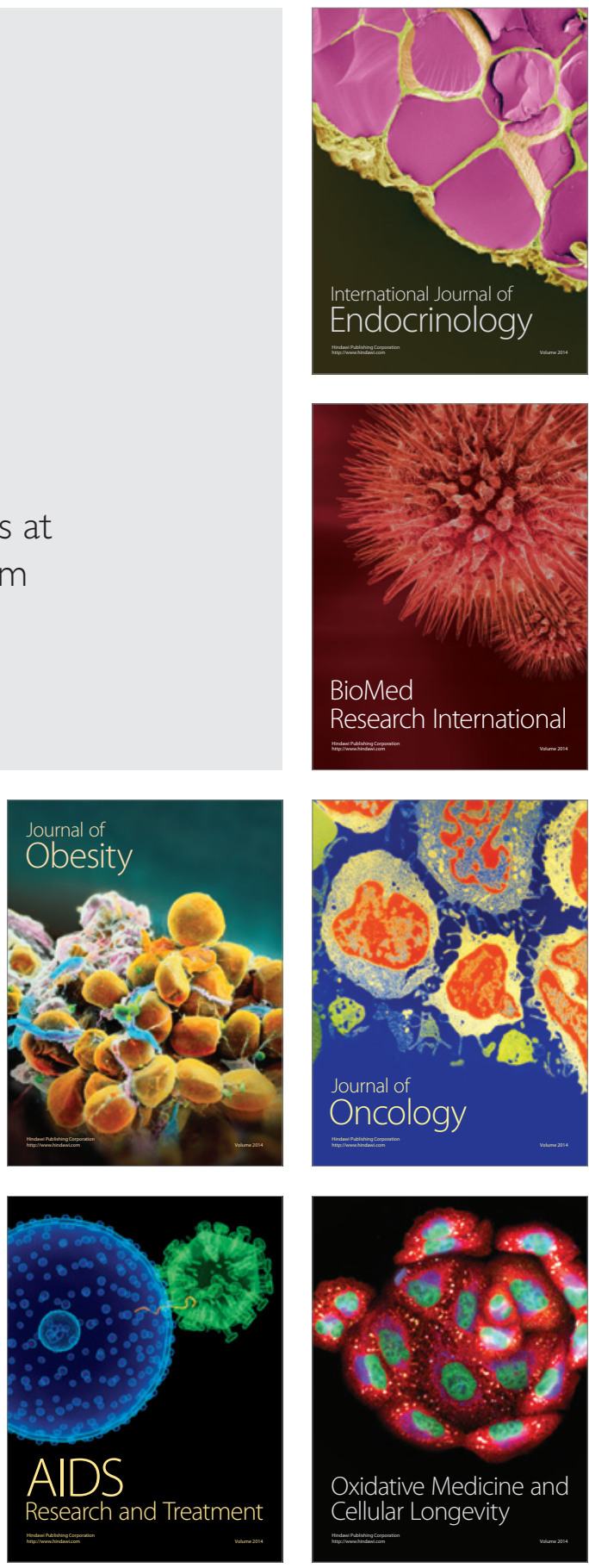